\title{
Effect of Waste on Population in Umbada Locality, Khartoum State, Sudan
}

\author{
Ismail Mohamed Fangama $^{1^{*}}$ and Wamda Bushra Hamed ${ }^{2}$ \\ ${ }^{1}$ Department of Botany \& Environment, College of Forestry \& Range Science (SUST), Sudan \\ ${ }^{2}$ Department of Natural Resources, Ministry of Agriculture, Sudan
}

*Corresponding author

\section{Key w ords \\ Accumulation of waste, Environment, Landfill and population \\ Article Info \\ Accepted: 10 October 2018 Available Online: 10 November 2018}

\section{A B S T R A C T}

The study was conducted in Umbada Locality, Khartoum State. The problem of the research was the reflection of accumulated waste on the environment of the area such as air, water, soil and sight pollution as well as the nasty smell affected the population. The objective of research is to know the effect of waste on population settled surrounding the landfill in Umbada Locality. The methodology of research was based on the field visit, a questionnaire designed a questionnaire with several questions directed to the citizens within the study area Also the relevant authorities such as the Yolk and the Department of Environmental Health were interview. The visual observations were made in all the places to monitor places of waste accumulation within the study area. The result revealed that $88 \%$ of respondents confirmed that waste affect the population on Water and air pollution leads to the spread of chest diseases such as asthma, allergies, spread of malaria and typhoid fever diseases as a result of pollution. The results indicated that, the presence of accumulated waste inside residential neighborhoods, in front of houses, public roads and branch, inside the empty spaces. These wastes have negative impact on the surrounding environment to human beings. The study recommended that innovation of new scientific systems and processes to collect the waste and disposal.

\section{Introduction}

Population increase, economic progress, expansion in urban areas, rapid industrial development, and rising standard of living have all contribution to a sharp rise in solid waste generation in most countries (Farag, 2005). Health and safety issues arise from improper management of solid waste (MSW). Insects and rodents vectors are attracted to the waste and can spread diseases such as Cholera and Dengue fever. Using water polluted by MSW for bathing, food irrigation and drinking water can also expose population to disease organisms and other contaminants (Pervez and Kafeel, 2013). Exhaust fumes from waste collection vehicles, dust stemming from disposal practices and the open burning of waste also contribute to overall health problems (Pervez and Kafeel, 2013). The uncontrolled burning of accumulated wastes creates smoke and other air pollutants which release toxic substances in the environment harm the people (Fangama, 2016). Bad waste management practices can result in land and air pollution and cause respiratory problems and other adverse health effects as contamination are absorbed from the lungs 
into other parts of the body (Fangama, 2016). Municipal solid waste streams can bleed toxic materials and pathogenic organisms into the leachate of dumps and landfills. (Leachate is the liquid discharge of dumps and landfills; it is composed of rotted organic waste, liquid wastes, infiltrated rainwater and extracts of soluble material.) If the landfill is unlined, this runoff can contaminate ground or surface water, depending on the drainage system and the composition of the underlying soils (USAID, 2009). Increase disease transmission or otherwise threaten public health: Rotting organic materials pose great public health risks, including, serving as breeding grounds for disease vectors. Waste handlers and waste pickers are especially vulnerable and may also become vectors, contracting and transmitting diseases when human or animal excreta or medical wastes are in the waste stream. Risks of poisoning, cancer, birth defects, and other ailments are also high (USAID, 2009).

In locations where shantytowns or slums exist near open dumps or near badly designed or operated landfills, landslides or fires can destroy homes and injure or kill residents. The accumulation of waste along streets may present physical hazards, clog drains and cause localized flooding (USAID, 2009).

\section{Research problem}

In Ombada locality, waste accumulates significantly along the aspects of the main roads and within the streams of rain water draining and at the entrances to major key markets. Also piling up of waste in the fields of stadiums and in front of the houses too, in the west of the locality, accumulate livestock residues in the livestock markets also, in the North-west of this, piling up poultry farms and feed production waste, as well as medical waste from small medical centers and Ombada hospital. The random open burning of waste emits obnoxious smell, different gases which have impact on the environment which in turn would affect human, animals and plant life. This effect in the environment of the area such as air, water, soil and sight pollution as well as the nasty smell affected the population.

\section{Research objective}

The objective of research is to know the effect of waste on population settled surrounding the landfill in Umbada Locality, Khartoum State, Sudan.

\section{Materials and Methods}

The methodology of research is based on the following:

\section{The field visit}

Field visits conducted on public streets, markets, hospitals, residential neighborhoods and landfill to see the accumulated waste, types of waste present.

\section{A questionnaire}

Design a questionnaire with several questions directed to the citizens within the study area included the types of accumulated waste, the place of accumulated waste, the main reasons that led to the accumulation of waste and the effect resulting from the accumulation of waste.

\section{Interview the relevant actors}

The relevant authorities such as the Yolk and the Department of Environmental Health interview and discussed with them the problems of accumulation waste on people.

\section{Visual observation}

Visual observations are made by considering, in all the places within the study area and to 
monitor places of waste accumulation within the study area.

\section{Results and Discussion}

\section{Impact of waste on population}

In table $1,88 \%$ of respondents confirmed that waste affect the population on Water and air pollution leads to the spread of chest diseases such as asthma, allergies and crises. The spread of malaria and typhoid fever diseases as a result of pollution. The spread of kidney failure due to water pollution. Visual pollution as a result of the accumulation of waste. Deterioration of human health in general as a result of contamination of the surrounding environment. Breeding flies leads to the spread of diarrheal diseases. This is similar report of (USAID, 2009)" In locations where shantytowns or slums exist near open dumps or near badly designed or operated landfills, landslides or fires can destroy homes and injure or kill residents. The accumulation of waste along streets may present physical hazards, clog drains and cause localized flooding" (Plate 1).

\section{Impact of the landfill on the soil}

From table $264 \%$ of respondents answered that the impact of waste on the soil as follows: Leveling the soil surface by drilling landfill and thereby become invalid armed building, the presence of waste reduces the fertility of the soil and makes it unsuitable for cultivation, lead to contaminate groundwater, reduces growth plants on the soil surface, chemicals + sewage lead to soil contamination and lack of suitability for cultivation in the future, change the nature of the soil and the installation of components, breeding insects and pests in the soil, adding the remnants of edible oils into the soil reduces fertility. These results are similar report by (USAID, 2009). If the landfill is unlined, this runoff can contaminate ground or surface water, depending on the drainage system and the composition of the underlying soils.

\section{Effect of the landfill on the water}

In table 3, 62\% of respondents said that the impact of waste on the water as follows: Contamination of drinking water with bacteria and disease-causing germs, breeding of flies and insects inside the water, leading to the spread of diseases, contamination of surface and groundwater sources of toxic substances and chemicals, turning the smell of drinking water to the foul smell like the smell of the echo, The taste of the water turned into a salty taste. These results are agreed with (USAID, 2009), mentioned that "Municipal solid waste streams can bleed toxic materials and pathogenic organisms into the leachate of dumps and landfills. Solids can cause sedimentation and change stream flow and bottom habitat" (Plate 2).

\section{The impact of the waste on the air}

In table $484 \%$ of respondents confirmed that waste affect air due to: The spread of dust in the atmosphere in large quantities, the spread of odors emitted from the food scraps, dead animals and sewage. Breeding insects such as mosquitoes and flies spread in the air. Air pollution is due to toxic gases, such as methane and carbon dioxide.

Burning waste within the landfill leads to the spread of smoke in the air. The proliferation of plastic bags in the air and attached to wires electricity. This result the same as stated by (Fangama, 2016), the uncontrolled burning of accumulated wastes creates smoke and other air pollutants which release toxic substances in the environment harm the people. These results also are agreed with (USAID, 2009), reported that, "when the organic wastes are disposed of in deep dumps or landfills, they 
undergo anaerobic degradation and become significant sources of methane, a gas with 21 times the effect of carbon dioxide in trapping heat in the atmosphere. Garbage is often burned in residential areas and in landfills to reduce volume and uncover metals. Burning creates thick smoke that contains carbon monoxide, soot and nitrogen oxides, all of which are hazardous to human health and degrade urban air quality". Plate 3 explains the remains of burning the waste in the landfill flooding."

\section{Impact of waste on animals}

Table 5 showed that, $68 \%$ of respondents confirmed that the waste has an effect on the animals due to: when animals eat plastic bags that lead to them to die. When eat leftovers fermented lead to disease and weak health, such as diarrhea. Air, water and soil pollution affects the health of the animal such as the man. This result agreed with (USAID, 2009). "The waste impact on animals in case of "When solid waste is dumped into rivers or streams it can alter aquatic habitats and harm native plants and animals. The high nutrient content in organic wastes can deplete dissolved oxygen in water bodies, denying oxygen to fish and other aquatic life form."

\section{Impact of waste on landscape}

In table $680 \%$ of respondents confirmed that waste have an effect on the landscape due to: Waste accumulated lead to visual pollution. Accumulation of waste side uncivilized reveals and demonstrates the failure of society. The accumulation of waste distorts the overall appearance of cities and aesthetic appearance. The accumulation of plastic bags and hanging on the trees leads to deformation of the landscape, these lead to a distortion of the entrances to the city and disturbing the public mood. These results are the same as reported by (USAID, 2009). "Sitting dumps or landfills in sensitive ecosystems may destroy or significantly damage these valuable natural resources and the services they provide".

Also added "The unpleasant odor and unattractive appearance of piles of uncollected solid waste along streets and in fields, forests and other natural areas can discourage tourism and the establishment and/or maintenance of businesses".

Table.1 The impact of waste on population

\begin{tabular}{|r|c|c|}
\hline Description & Frequency & Percentage \\
\hline Yes & 44 & 88 \\
\hline No & 2.0 & 4.0 \\
\hline No answer & 4.0 & 8.0 \\
\hline Total & 50 & 100 \\
\hline
\end{tabular}

Table.2 Impact of the landfill on the soil

\begin{tabular}{|r|c|c|}
\hline Description & Frequency & Percentage \\
\hline Yes & 32 & 64 \\
\hline No & 10 & 20 \\
\hline No answer & 8.0 & 16 \\
\hline Total & 50 & 100 \\
\hline
\end{tabular}


Table.3 Effect of the landfill on the water

\begin{tabular}{|r|c|c|}
\hline Description & Frequency & Percentage \\
\hline Yes & 31 & 62 \\
\hline N0 & 10 & 20 \\
\hline No answer & 9.0 & 18 \\
\hline Total & 50 & 100 \\
\hline
\end{tabular}

Table.4 The impact of the landfill on the air

\begin{tabular}{|r|c|c|}
\hline Description & Frequency & Percentage \\
\hline Yes & 42 & 84 \\
\hline No & 4.0 & 8.0 \\
\hline No answer & 4.0 & 8.0 \\
\hline Total & 50 & 100 \\
\hline
\end{tabular}

Table.5 Impact of waste on animals

\begin{tabular}{|r|c|c|}
\hline Description & Frequency & Percentage \\
\hline Yes & 34 & 68 \\
\hline No & 9.0 & 18 \\
\hline No answer & 7.0 & 14 \\
\hline Total & 50 & 100 \\
\hline
\end{tabular}

Table.6 The impact of the landfill on the landscape

\begin{tabular}{|r|c|c|}
\hline Description & Frequency & Percentage \\
\hline Yes & 40 & 80 \\
\hline No & 4.0 & 8.0 \\
\hline No answer & 6.0 & 12 \\
\hline Total & 50 & 100 \\
\hline
\end{tabular}

Plate.1 Waste accumulated in the road nearby the population settlement (2016)

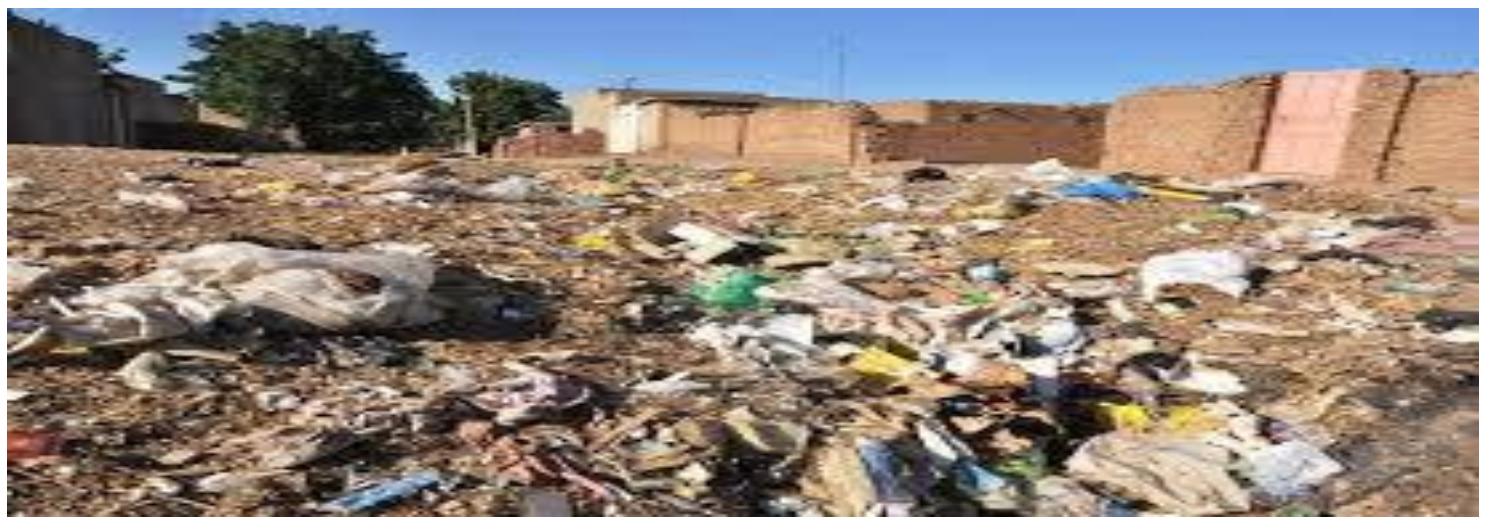


Plate.2 Waste accumulated in the stream carried by rainy water (2016)

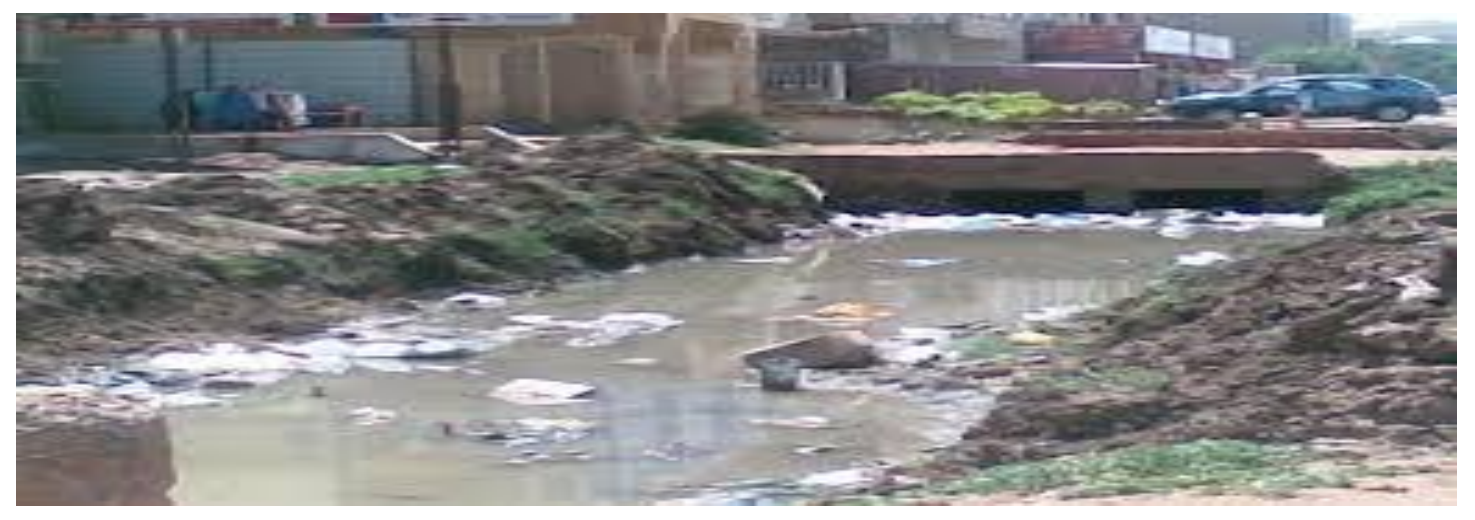

Plate.3 Remaining of ash after burning the waste (2016)

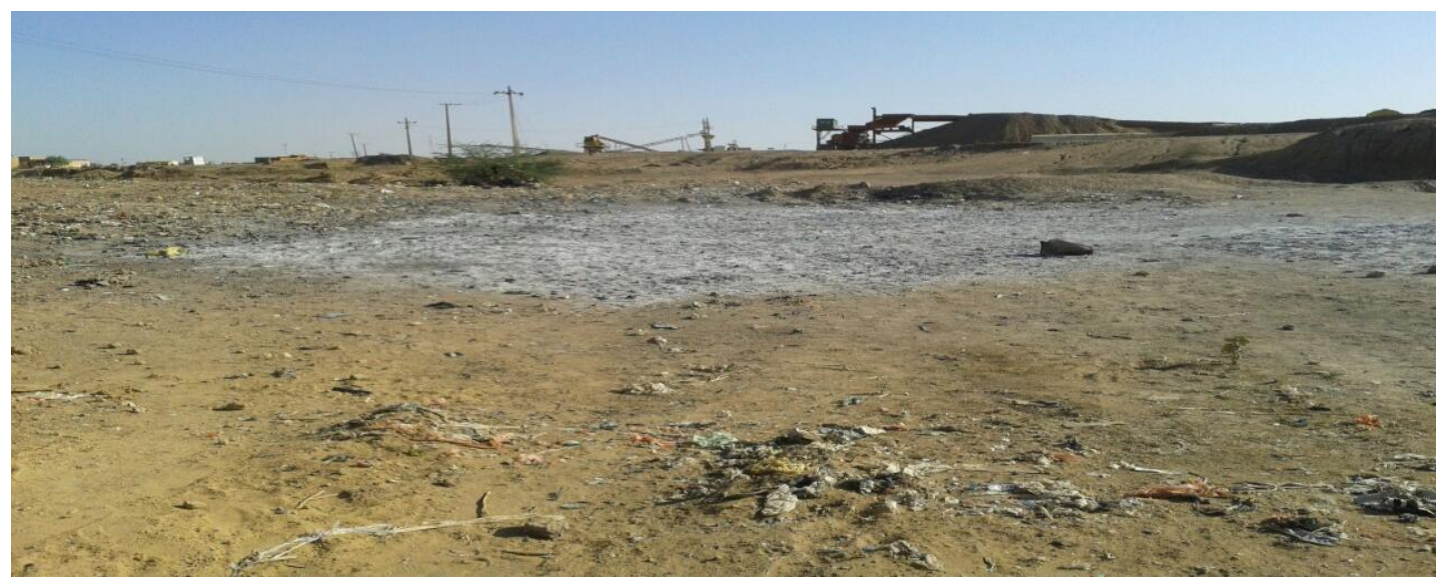

\section{Observations}

It observed that the piles of ash were indicated that there are large amounts of smoke and dust emitted from there as such of the presence of huge waste. The landfill causes the diminishing of the importance of the neighboring scenery of the area. The cars drivers usually transport the waste and unloaded out of the landfill near the settlement area. In addition to the nasty odor emitted from waste and smoke from burning of tires covered the sky.

The results indicated that, the presence of accumulated waste inside residential neighborhoods, in front of houses, public roads and branch, inside the empty spaces of the houses, in front of shops and in the markets, and within the landfill area. This waste consists of food scraps, plastic bags, glass, metal pieces, construction waste, dust, smoke, leaves, twigs and leaves of trees, remnants of animals, dead animals, sewage, water restaurants. These wastes have negative impact on the surrounding environment to human beings, the air, water, soil and animal and vegetation and human health. The burning of the waste pollutes the air and the spreads nasty odors in the atmosphere, buries vegetation, pollutes the surface water, fresh water, causes many diseases to humans, such as gastrointestinal and respiratory diseases and distort the general appearance of the city and visual pollution and disturb the mood of the citizen. 


\section{Recommendations}

The study comes up of the following recommendations: The household must sorting the waste even easier for workers waste transported to landfill final disposal properly.

Local authority is responsible for waste collection and disposal to intensify hygiene campaigns and the number of times the transfer of waste from residential neighborhoods and roads in the month. Innovation of new scientific systems and processes to collect the waste and disposal.

Strictly laws should be hold to penalt all those who work on the scattering of waste indiscriminately in not intended places. Development of an independent supervisory body to monitor the officials for the transfer of waste to the landfill final

\section{References}

Fangama, I.M. (2016). Impact of Waste on Environment at Kerrey Area Khartoum State. International Journal of Engineering Science and Innovative Technology. (3)5, 425-428.

Farag. A. El-Mabrouk (2005). Ph.D. Faculty of Engineering, Benghazi University Benghazi, Libya.

Pervez, A. and Kafeel, A. (2013). Impact of Solid waste on Health and the Environment. Department of Civil Engineering, COET, BGSB, University, Rajouri, J \& K, India. Department of Civil Engineering, F/O Engineering \&Technology, JMI, New Delhi, India.

United Nation International Development (USAID, 2009). Environmental Guidelines for Small-Scale Activities in Africa.

\section{How to cite this article:}

Ismail Mohamed Fangama and Wamda Bushra Hamed. 2018. Effect of Waste on Population in Umbada Locality, Khartoum State, Sudan. Int.J.Curr.Microbiol.App.Sci. 7(11): 1327-1333. doi: https://doi.org/10.20546/ijcmas.2018.711.154 